\title{
Eighth In A Series
}

\section{Issues Challenging Rangelands Down Under}

\section{The future of range management in Australia hinges on taking a holistic, regional approach and continuing to attract people to the profession.}

\author{
By Andrew Ash and Mark Stafford Smith
}

Respectively: CSIRO Sustainable Ecosystems, Private Mail Bag, Aitkenvale, , QLD 4814 and CSIRO Sustainable Ecosystems, PO Box 2111, Alice Springs, NT 0871, Australia.

Over $70 \%$ of Australia is rangeland. This vast area of rangelands has a great diversity of ecosystems from arid shrublands and grasslands to semi-arid woodlands and sub-tropical and tropical savannas. The rangelands are an important part of Australia's social and cultural history for both indigenous and non-indigenous peoples.

This rich history, particularly the more romantic pioneering elements, led to a strong affinity of urban communities for rangelands. However, in recent decades the empathy of city dwellers for rangelands and their people has been declining largely because of Australia's trend towards urbanization and globalization.

Although the primary land use in the rangelands is pastoralism, its economic contribution of about A $\$ 1$ billion annually is considerably less than that of mining (A\$14 billion) and tourism (A\$2.2 billion). However, rangelands also provide other important non-economic values, including high species diversity, unique habitats and traditional hunting and gathering by indigenous peopleswho account for $18 \%$ of rangeland residents and own over $20 \%$ of the area.

The Australian rangeland profession is unlike those of the USA and South Africa, which have a long history of scientific endeavor in rangeland management. Australia's rangelands were scientifically ignored for a considerable part of our agricultural history as most effort focused on agronomic solutions based on European farming practices and overcoming the limitations of Australia's relatively infertile farming lands and variable climate. There were

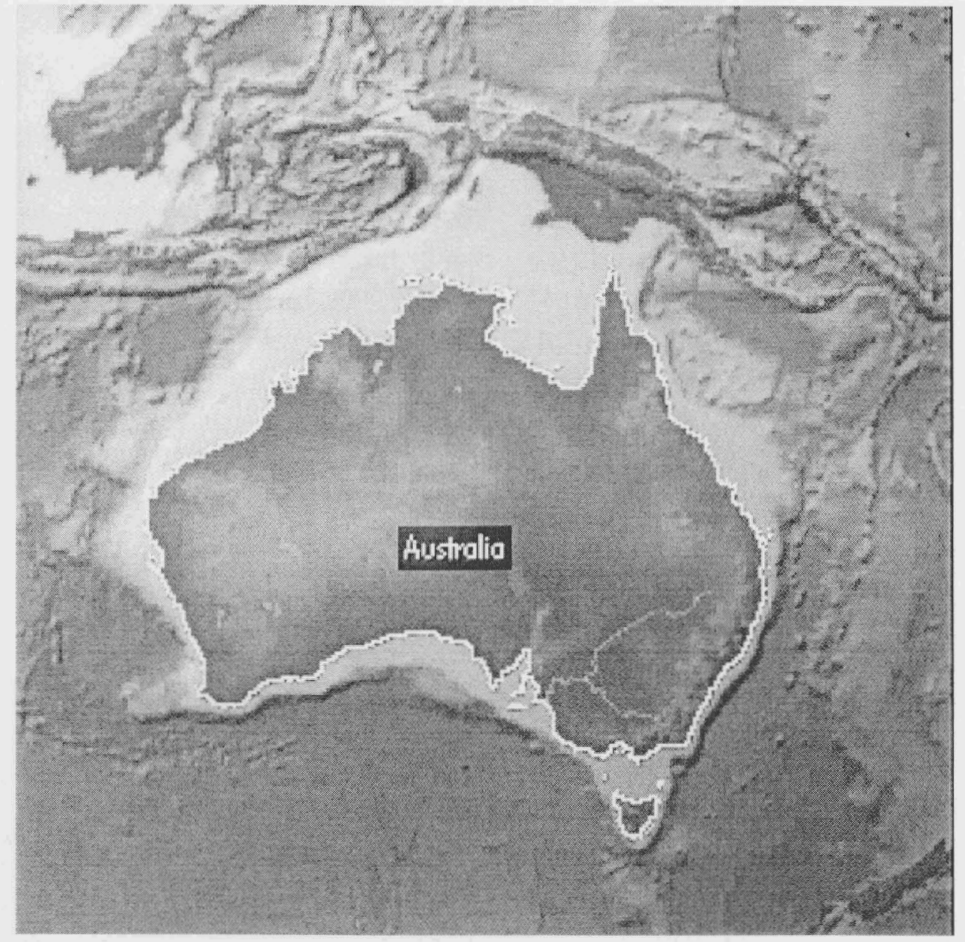

no formal rangeland schools as agricultural science dominated most Australian universities. The best articulated calls for a more formal approach to rangeland management came from a government scientist, Francis Radcliffe, as late as the 1940s when concepts of range science had long been established in the US.

The Australian Rangeland Society was formed in 1975 to provide an organizational framework that would allow the few professionals working in rangelands to exchange ideas and develop a more structured approach to tackling issues in rangeland management. About the same time, more formal teaching of rangeland science was occurring in a couple of universities, usually within Botany departments.

While this late genesis of a professional rangeland society within Australia has meant that we still have a relatively limited biophysical, economic, social and cultural understanding of rangelands, it has not led to entrenched views or paradigm paralysis. For example, the Australian rangeland profession was not tightly bound to Clementsian views of plant succession versus models based on non-equilibrium theory, and so was more easily able to discuss and debate the proposed new paradigms. Also, while the Australian rangeland profession is numerically small it has a diverse array of interests beyond the traditional focus on 
livestock grazing management. These diverse interests have been reflected in special issues of The Rangeland Journal, Proceedings of the Biennial Conferences of the Australian Rangeland Society and the International Rangeland Congress held in Australia in 1999.

\section{Australian Rangelands Today}

There are a number of issues and problems facing Australian rangelands and their communities today. Some of these stem from past management mistakes while others are a result of rapidly changing economic and social values both within Australia and globally. The most important of these contemporary issues are: (1) Land degradation and species loss; (2) Feral animals and weeds; (3) Declining pastoral industry economics; (4) Accommodating multiple land uses (pastoralism, tourism, aquaculture etc); (5) Intensifying rangeland use to remain economically viable; (6) Changing land tenure and access insecurity, which is a particular issue for indigenous, pastoral and mining communities; (7) Structural and social problems at the regional scale in rangelands - these are not just internal issues but are closely tied to decisions made by governments, large corporations and banks in big cities in Australia and overseas; (8) A disconnection between the urban communities and the rangelands-more than $80 \%$ of Australia's population now lives within $50 \mathrm{~km}$ of the coast; (9) The urban communities demanding sustainable use of the rangelands; and (10) International market pressure to attain "green" accreditation and have a well defined and implemented environmental management systems framework in place.

Likely future drivers of rangeland change include: (1) Increased marginalization of rangelands in world and national affairs; (2) Institutions (government and community organizations) playing a key role in shaping rangeland societies and rangeland productivity rather than individual enterprises and market forces; and (3) Energy politics, technology and trade significantly influencing rangelands in the next 200 years.

\section{How Should These Issues Be Addressed?}

In dealing with problems in the past such as land management, pests, weeds and economics, the traditional response from the rangeland profession has been, "We need more and better information." This has led to more research, usually biophysical, but many of the problems remain. Some of this can be attributed to undertaking research at a spatial scale that is not very relevant to management. This is a particular problem in rangelands in Australia because of their extensive scale of management and their heterogeneity.

So, while we have collected much good information and improved our understanding of soil, plant and animal processes at small scales we have had difficulty in translating this understanding to assist management at larger scales. In addition, there has been an increasing trend in recent years to applied research with a decrease in emphasis in strategic research, which is likely to provide greater benefits in the medium to long-term.

Assuming there is enough biophysical understanding, the next solution to solving management problems has been, "We need more and better extension and better integration of existing information." This philosophy has been adopted and applied by various institutions and agencies with the belief that by emulation of successful enterprises in the region many current problems will be solved.

However, the reason many current problems still exist is due to economic, cultural, social and institutional constraints. These constraints are generally beyond the influence and traditional interests of research, development and extension agencies and professionals in the rangelands.

1) Holistic Approach Needed. We believe the key to addressing current and future rangeland problems is a more holistic approach that integrates ecological, economic, social, cultural and institutional issues using a multidisciplinary approach. The traditional technocentric and reductionist paradigm that has been so popular in the past cannot on its own deliver the range of complex solutions necessary to address the current needs of rangelands. While the more traditional biophysical ecological and production research and extension still has much to offer, it will only be of value if it is undertaken at appropriate scales and only if it interacts with socio-economic and institutional systems.

2) Address Issues By Region. Issues should be addressed in a regional context. This is important for two reasons: (1) There is strong evidence that a participatory approach building strong partnerships between key regional stakeholders is a successful means of achieving more sustainable and equitable resource use in rangelands; and (2) National rangeland policies that are set in a regional context rather than assuming that the rangelands are biophysically and socio-economically uniform are likely to lead to better environmental, economic and social outcomes. This would require giving private enterprise freedom to pursue profit where the environment is resilient but provide greater public control where private interest may not produce socially and ecologically desirable outcomes.

Presently, the greatest constraint on coordinated action in rangelands in Australia derives from the fact that these lands spread across five political jurisdictions, with top priority in none. Thus a pre-requisite for future rangelands research may well be the establishment of some cross-jurisdictional forum to focus on rangelands. The other alternative is that future research will really be in the context of regionalization with no special recognition of these regions rangeland nature.

3) Attract Professionals To Rangelands. There is a clear recognition among most rangeland professionals that these approaches are the way of moving forward. However, there has been a significant decline in the number of rangeland professionals in Australia over the last 10 years, both in state and federal agencies. So at the same time we need to broaden our disciplinary approach to addressing rangeland problems, national and state governments are reducing their efforts in the rangelands.

This reduction in effort in the rangelands reflects a broader decline in rural 
towns in Australia, compounded by the withdrawal of government and non-government services. As the rural towns become less attractive places to live, it becomes difficult to recruit professionals into the rangelands.

In a positive move to overcome the decline in rangeland professionals, a new educational initiative called Rangelands Australia has been put in place. Rangelands Australia is a national initiative to provide a cooperative approach to education, training and research for the betterment of Australia's rangelands and its communities. The focus for the implementation of
Rangelands Australia is through the establishment of a center of excellence in rangeland management education, training and research located at the University of Queensland Gatton Campus with a nationwide network of rangeland centers and online services.

The regional, multi-disciplinary approaches needed to provide rangeland solutions are starting to be adopted by rangeland professionals. However, for these approaches to become more widespread the individual skills of our rangeland professionals needs to broaden; we need ecologists with better business skills and appreciation of the socio-eco- nomic environment in which they work, social scientists who understand rangeland ecology and production systems, and we need teams with a diversity of skills who can work well together. Rangeland professionals must also be more politically astute if we are to influence policy to overcome some of the institutional constraints that bedevil the range.

\section{Acknowledgements}

Many thanks to Guy Fitzhardinge, Margaret Friedel, David Eldridge, Ron Hacker, David Freudenberger, Jim Noble and Rob Richards for providing many of the ideas expressed in this paper.

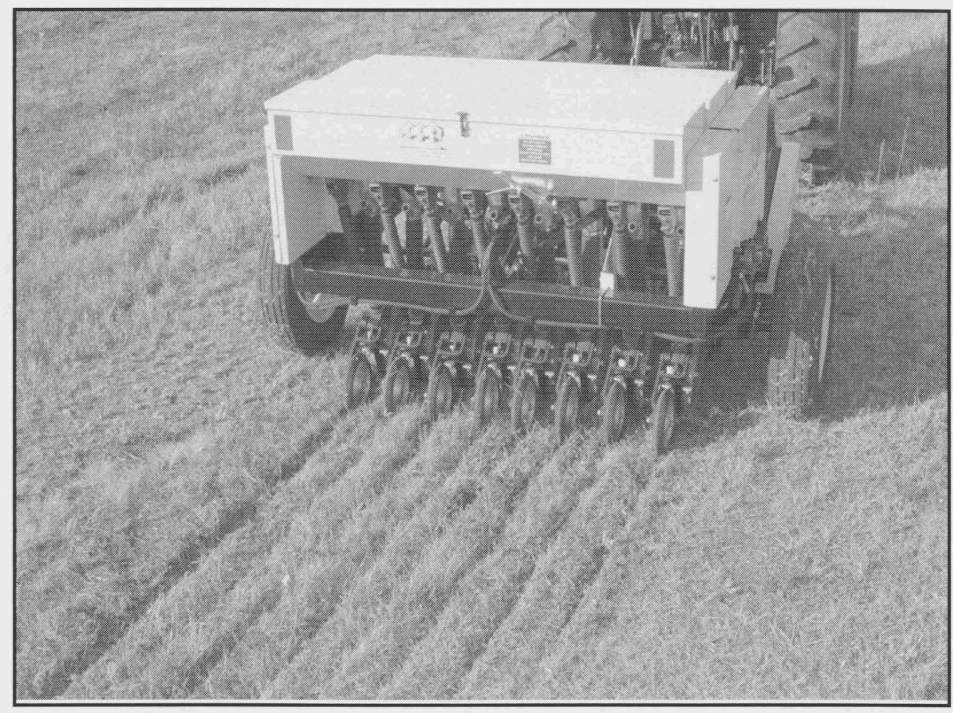

NG The "Trillion" - shown at right, is the ideal broadcast seeder for wildflowers, turf grasses, and fluffy/chaffy prairie seeds. Unit has three types of seed boxes and combines the truax seed delivery system with two Brillion ${ }^{\circledast}$ cultipack rollers.
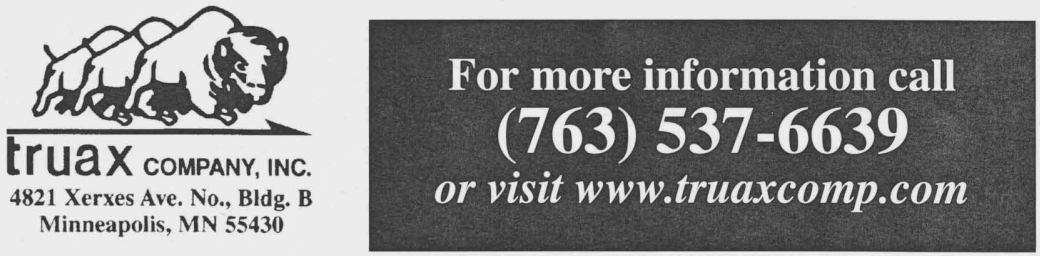

\section{PERFORMANCE.}

Superior design, top-quality materials, and meticulous hand-built construction are what set truax seeding equipment apart from the competition. You'll find these in every truax seeder from the small, hand-cranked, Seed Slinger that lets you broadcast fluffy seeds and grasses together by hand, to the famous Flex II seed drill pictured at left, which interseeds native grasses, turf grasses, fluffy seeds, small grains, wildflowers, even legumes.

The result is outstanding seeding performances even in the most challenging environments! - and durability that will last for decades.

If you want dependable seeding performance, you want a truax!

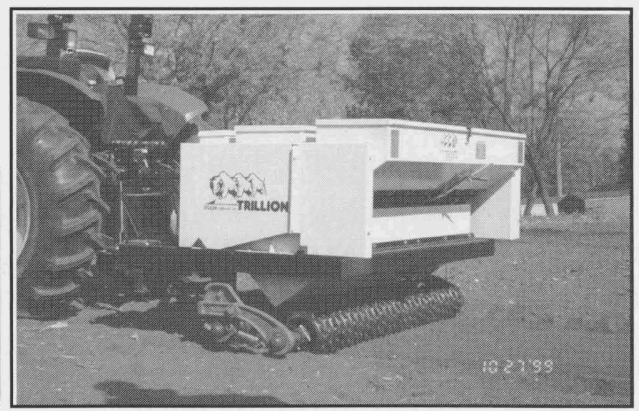

